\title{
TITLE:
}

\section{$<$ Note $>$ The Sudden Decline of a Community of Chimpanzees at Gombe National Park}

$\operatorname{AUTHOR}(\mathrm{S}):$

Greengrass, Elizabeth

CITATION:

Greengrass, Elizabeth. < Note> The Sudden Decline of a Community of Chimpanzees at Gombe National Park. Pan Africa News 2000, 7(1): 5-7

ISSUE DATE:

2000-06

URL:

http://hdl.handle.net/2433/143385

RIGHT:

Copyright (C) Pan Africa News. 


\section{<NOTE> \\ The Sudden Decline of a Community of Chimpanzees at Gombe National Park}

\section{Elizabeth Greengrass}

Gombe National Park, in western Tanzania is home to three communities of chimpanzees. The Mitumba (northernmost) community ranges within the Mitumba, Kavusindi and Busindi valleys. This community presently consists of twenty-five known individuals being habituated for tourism. The Kasekela (centrally ranging) community is the main study group in the Park and has been habituated to humans since the early 1960s. Numbering between forty and fortyfive individuals, presently it ranges from its northern most limit, in Rutanga valley as far south as Nyasanga. Historically, the range today may be at its largest since records begun in the early 1960s.

Up until the start of 1999 , very little was known about the southern community, also referred to as the Kalande community, which has remained unhabituated to humans since research began at Gombe, forty years ago. A habituation project was underway during the 1980 's, which estimated numbers to be in the magnitude of sixty to eighty individuals, making it the strongest community in the Park. The range extended as far north as Kahama valley and as far south as the southern most valley of Nyamagoma.

This study was initiated because all evidence pointed to a dramatic reduction in the number of this community since the mid-1990s. There were no longer any reports of sightings of large groups in the area and worryingly, the neighbouring Kasekela community had increased their community range two valleys south to Nyasanga without meeting any resistance. This indicated that the number of males defending the southern community's range had fallen.

The aims of the project are fourfold: to estimate the density and population of chimpanzees remaining in the south; to study patterns of association and distribution between 
community members; to study the vegetation and various aspects of the chimpanzee ecology and to identify the underlying causes of falling numbers.

The study has so far shown our initial suspicions to be correct: The numbers of the southern Kalande community have fallen sharply over a short time period. Analysis of data so far received on bed counts (for October and November 1999) show a mean number of nineteen chimpanzees remaining. Using a transect of bed counts may not prove to be an accurate method of calculating density, though, since it assumes that chimpanzees beds randomly throughout their range. This is not so since group movements depend largely on factors such as the whereabouts of fruiting crops at different times of the year. Direct observation, however, gives no evidence of more than twenty to thirty chimpanzees remaining. This is supported by the fact that the present community range is no larger than the present Mitumba community range, which has supported in its recent past between twenty-five and thirty chimpanzees. Research has also shown that both food quality and quantity in the Kalande's range is much poorer than that in either of the other two communities' in the Park. It is therefore unlikely to support more.

Almost all known cases of poaching have occurred in the southern area of the Park. During the latter half of 1998 , day long surveys produced evidence of poaching activity or trespassing in this area, e.g. snares, hunters, hunting dogs, local villagers fleeing from inside the Park and the case of a dead male chimpanzee found without his hands and genitals. Since this project has commenced, however, the area has been more thoroughly surveyed by researchers than preceding years. Snares have yet to be discovered in any of the five valleys under study, and the lower frequency with which poaching has been detected seems to imply that research has played its part in reducing poaching activity as it does in other parts of the Park. Of real concern, however, are recent incidents of semi-automatic gunfire being heard at night in this area of the Park.

Other factors may have contributed to the decline, such as disease. For example, the Kasekela community became victims of a polio

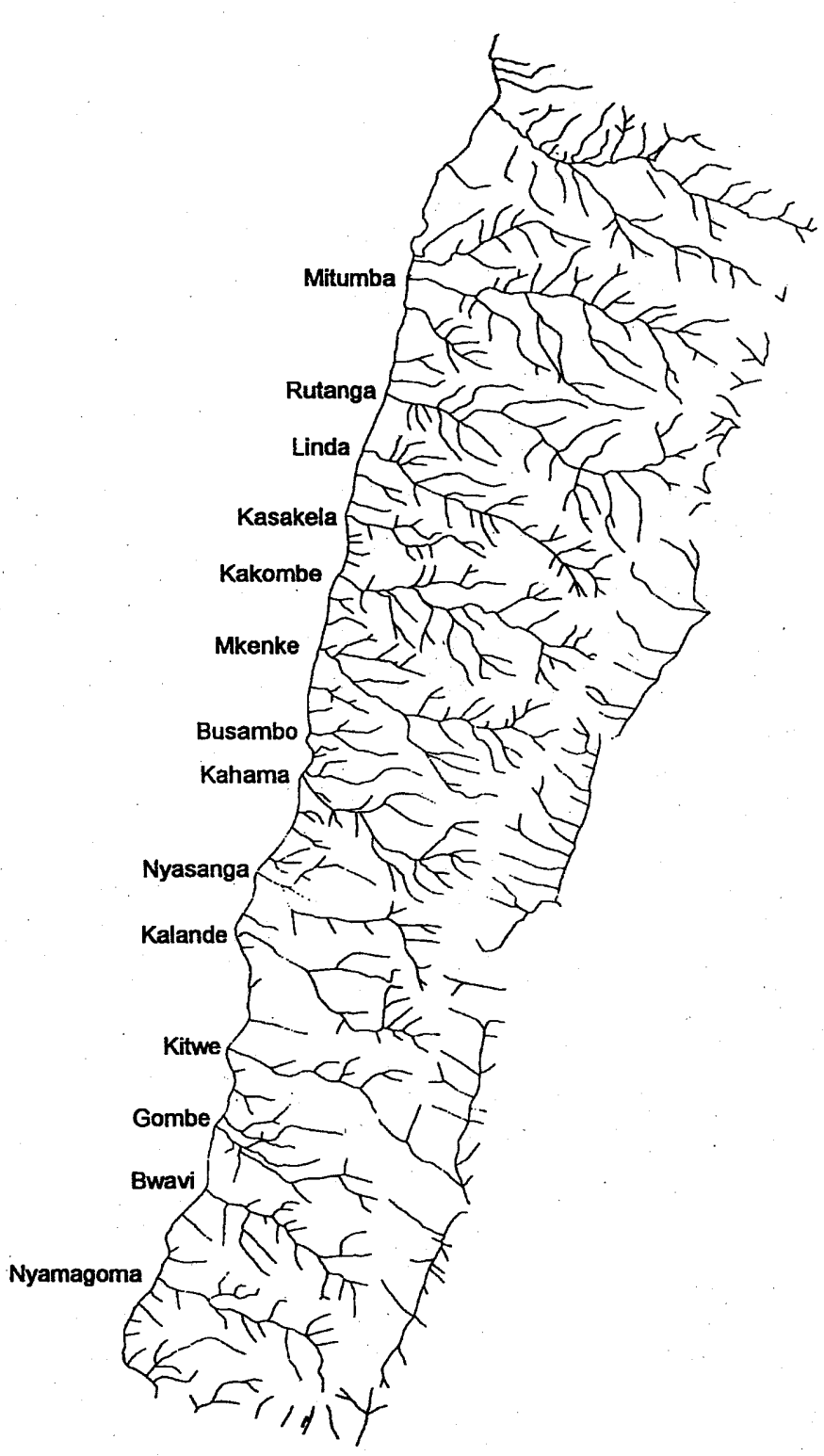

epidemic in the late 1960s, a respiratory illness in 1987 and a scabies epidemic in 1998. In February 2000 , a respiratory disease claimed the lives of two adolescent males and evidence collected at the time revealed that humans could well have been the vectors of the disease. It is quite possible that some of the other epidemics were also transmitted from humans, although no evidence was collected at the time. The Kalande community, however has had very little contact with humans (a habituation project was started in the 1980s) and we believe that the evidence, as well as the extent of the decline in such a short period of time, points to poaching as the main cause. Traditionally, poaching has targeted 
example, people in the Southern Highlands of Tanzania have been reported for the first time to eat monkey, which is presently considered a great delicacy (1).

The closest town to Gombe is the port town of Kigoma, fifteen kilometres south of the Park, with an established trade route between Burundi, D.R.C. (referred to here as Congo), Tanzania and Zambia. Since 1996 there have been rumours of bushmeat on sale within Kigoma and an animal trade probably exists,although its extent is unknown. For example, there have been a number of cases, over the years, of people, including Congolese, passing through with, or trying to sell baby chimpanzees in Kigoma. Two sets were caught by the Kigoma authorities.

An influx of Congolese refugees may have increased the trade in endangered species and bushmeat between Tanzania and Congo and within Tanzania itself. During 1998 NGO employees visiting Gombe showed researchers photographs of bushmeat on sale within the Lugufu Camp, near the Lilanshimba Hills, a known chimpanzee habitat. Some parts were almost certainly those of chimpanzees. (Congolese do not share the Tanzanian traditional taboo against eating primates).Villages on the southern side of the Park have a large Congolese population. Incidents of bushmeat trafficking between these coastal villages and Kigoma are known and the closest resource for this trade could be the Park itself. The discovery of the decomposed remains of a female chimpanzee, two valleys from the southern border, coincided with the incident of two Congolese approaching expatriates in Kigoma town, trying to sell a live infant chimpanzee allegedly held in Mtanga, the village along the southern border of the Park. Over the last few years firearms have become readily available in this region, due to its close proximity to the wars in Burundi and Congo.

Poaching for game is only one of the resources under pressure at Gombe. The most common form of poaching is for wood, especially along the southern border and east along the Rift Escarpment. Along the southern border and within the southernmost valley of the Park, villagers from Mtanga cut trees for firewood.

Along the Rift Escarpment, Burundi refugees cut trees outside the Park to manufacture charcoal. Within just a few months, remaining stretches outside the Park will have disappeared all together and it is almost certain that the pressure on the Park for wood will grow.

Certainly the problems at Gombe are no way unique from the problems facing other protected areas. The fact, however, that Gombe is so small, just thirty-five kilometres squared and is not surrounded by a buffer zone, makes it extremely vulnerable to outside pressures. Research has been able to show that despite the dramatic fall in numbers of the southern community, it is still a cohesive community, which if allowed over the coming decades has the full potential to increase to its former numbers. Presently GSRC (Gombe Stream Research Centre) and TANAPA (Tanzanian National Parks) are working closely to eliminate all poaching activity for this end result to be achieved.

\section{REFERENCE}

(1) African primates 1997-1998 vol.3. 